\title{
El raudal de la Magdalena y la ciudad de Jaén durante la Baja Edad Media
}

\author{
$M^{a}$ del Consuelo Díez Bedmar*
}

Aunque la historia de la ciudad de Jaén ha sido estudiada con anterioridad desde diversos puntos de vista, hasta ahora no se había tenido en cuenta su estudio a través de uno de los elementos que más la han caracterizado a lo largo de los tiempos: el agua. En este artículo intentaré plantear la importancia de este factor a la hora de comprender el urbanismo que presentó la ciudad de Jaén durante la Edad Media, el porqué de la ubicación de los diferentes edificios públicos y privados, algunos ya desaparecidos, otros aún integrados y presentes en la imagen actual de la ciudad, y su estrecha relación con el Raudal de Agua de la Magdalena (entendiendo como raudal la conducción subterránea de aguas), fuente principal de su abastecimiento hidráulico hasta principios del siglo pasado (Figura I).

El hecho de que la Fuente de la Magdalena (lámina I) nazca intramuros ha proporcionado historicamente a la ciudad unas características peculiares.

Salvatierra y Alcázar (1996) realizaron un primer acercamiento a esta cuestión, centrándose en el período islámico. En su estudio pusieron de manifiesto la relación directa existente entre el Raudal y la ubicación de los diferentes baños árabes que han podido ser identificados en Jaén mediante la arqueología y la documentación escrita (los de Villardompardo y los del Naranjo), comprobando que el lími- te de rigidez del agua había tenido mucho que ver con la ubicación de los diferentes edificios islámicos urbanos, al encontrarse en su mayoría por debajo de éste, en un área cercana a la propia fuente. Del mismo modo se confirmaba un crecimiento de la ciudad durante el siglo $\mathrm{XI}$ en una dirección y sentido propicios para la conducción del agua por medio de una canalización hidráulica hacia los nuevos edificios, lo que corresponde con una ampliación del ramal principal (Figura 2). La prueba arqueológica de la existencia de este ramal apareció en el transcurso de una excavación llevada a cabo en el Palacio de los Uribe (1994) (Lámina 2). Por otro lado, se ha comprobado que el agua sobrante del uso urbano se dedicaba al riego de la huerta, a través de los diferentes arroyos que bajan la ladera del cerro de Sta. Catalina (SALVATIERRA, 1998; SALVATIERRA, SERRANO, PÉREZ, MARTíNEZ, en prensa).

Ante la carencia de documentación o hallazgos arqueológicos que lo constatasen, no se hacía alusión en su estudio a la localización de estructuras destinadas al abastecimiento público para el consumo. En el caso de otras ciudades, como Granada (ORIHUELA, VILCHES 199I) sí que se ha podido comprobar la existencia de una red de aljibes que se distribuían por toda la ciudad. En Jaén debemos suponer también su existencia. La lógica indica que éstos debieron existir a lo largo de la conducción principal (que discurriría aproximadamente por la

* Universidad de Jaén 
actual calle Magdalena Baja y por la calle Martínez Molina) y de los ramales secundarios, con la función de almacenar agua, regular su fuerza, establecer reservas para época de sequía, distribuirla hacia los diferentes edificios, además de servir para el abastecimiento de aquellos sectores de la población que carecieran de un pozo propio, y para el consumo del ganado.

\section{LA CIUDAD TRAS LA CONQUISTA}

Por su situación geográfica frente al reino nazarí de Granada, la ciudad recibe el título de "Guarda y defendimiento de los Reinos de Castilla". Desde el primer momento Jaén, como el resto de los municipios de la Corona Castellana, se dividió en collaciones, tanto para las funciones administrativas como para las eclesiásticas. Estas collaciones se estructuran como barrios organizados en torno a una parroquia (SALVATIERRA, 1993), que en muchos casos será el producto de la conversión de mezquitas en iglesias (I. de La Magdalena; I. de Sta. María), respondiendo a la política llevada a cabo en las ciudades que pasan a la Corona Castellana, mediante la que se consagran los antiguos lugares de culto islámico al cristiano.

Este proceso, sin embargo, no se produjo en todos los casos, posiblemente por el pequeño tamaño de la mayoría de las mezquitas de los adarves islámicos, lo que hizo a veces necesario buscar espacios más amplios para las diferentes iglesias, ya que las collaciones generalmente agruparon varios de estos adarves, con el consiguiente aumento de fieles para un mismo edificio, lo que conlleva una ampliación del espacio y un cambio de ubicación por razones urbanísticas (I. de S. Juan) (PÉREZ, ALCÁZAR, 1993). A este respecto puede servir como ejemplo lo que, según las últimas investigaciones, pasó en Granada, ciudad de la que se conoce un elevado número de mezquitas a través de los libros de hábices, y que no corresponden con las posteriores iglesias cristianas que son menos numerosas (GARCíA GRANADOS, inédito).
En cada una de las collaciones se procedía a tomar juramento a un ciudadano electo (que de ese modo se convertía en "jurado"), para que representara a la collación en el Concejo y trabajara con los magistrados. El jurado era agente de la Corona y su labor consistía en la elaboración de toda una serie de informes que se dirigían al Concejo. En realidad desde muy pronto no fue uno el elegido, sino dos por cada collación. Con el paso del tiempo, y debido a las gratificaciones económicas y sociales que se dispensaba a los titulares, el título pasó a ser hereditario dentro de la misma familia: un hijo o algún familiar próximo (VELASCO, 1987).

En casi todas ellas los aljibes musulmanes seguirán en uso y paulatinamente, a lo largo de los siglos XIII-XV serán destruidos o sustituidos por pilares-abrevadero, que a su vez en los siglos XIV-XVI serán primero remodelados y a veces trasladados, hasta pasar a convertirse en fuentes como las conocemos hoy, todo esto dentro de un proceso complejo y difícil de seguir, como resultado de una política de monumentalización que podemos poner en relación con la idea de utilizar la ciudad como escenario propagandístico de la nobleza, tanto laica como eclesiástica. Estas fuentes se encontraban, por lo general, adosadas a un muro, bien junto a una iglesia (La Magdalena), bien en las proximidades de una zona de mercado (Los Caños), sirviendo simultáneamente a las necesidades del consumo humano y al de las bestias.

Entre las fuentes más antiguas de las que tenemos noticia están las dos citadas de La Magdalena y la de los Caños. Esta última se encontraba, en su primera ubicación, adosada a la pared de la Pescadería como indica la documentación escrita y como se intuyó en el transcurso de la excavación del baño del Naranjo (SALVATIERRA, CASTILLO, CASTILLO, 1993). En el año 1558 con motivo de una ampliación del edificio se colocó en otro lado de la plaza ahora con ya como una fuente monumental '. Igualmente la fuente de la Magdalena sufrió un largo proceso de transformación y monumentalización hasta quedar como podemos verla hoy.

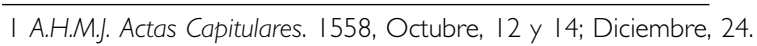


Con el cambio de mentalidad que sucede al asentamiento de la nobleza castellana, se produce también un nuevo sistema de estratificación social, que podemos ver plasmado en lo referente al disfrute del agua. Si en la cultura islámica, el agua es considerada un bien público, por su carácter de elemento indispensable e inestimable de purificación antes de la oración, por lo que debe llegar por igual a todos los sectores de la población, en la cultura cristiana occidental el agua, desde el primer momento, se patrimonializa y pasa a ser propiedad real, eso sí, sin olvidar los requerimientos de una población que podría rebelarse contra el poder establecido si se veía desposeida de un elemento que antes pertenecía a todos de manera comunal. Así observamos cómo en el siglo $\mathrm{XV}$ se le sigue dando una mayor importancia a la cantidad de agua que surte las fuentes públicas aunque signifique eliminar las demás derivaciones hacia propiedades privadas.

Este nuevo concepto del agua como bien económico y social explicaría el aumento de donaciones a particulares y de conducciones a inmuebles privados, tanto laicos como religiosos. Aunque para estos momentos carecemos de documentación que lo confirme, es un proceso que puede seguirse perfectamente en la documentación posterior (DÍEZ-BEDMAR, en prensa).

A tenor de lo visto hasta aquí, parece muy posible que desde el principio se introdujeran profundos cambios en el funcionamiento de la ciudad, pero al mismo tiempo puede afirmarse que, en este primer momento, la variación que experimenta la trama urbana fue casi nula. Las obras públicas, o las grandes construcciones, posiblemente se limitaron a la restauración y refortificación de las defensas.

Poco más podemos decir de este momento ya que las Actas Capitulares, así como la mayor parte de la documentación de este primer período, desgraciadamente ha desaparecido a lo largo de los tiempos, de los archivos locales y provinciales. Quizá otro tipo de documentación (pleitos, amonestaciones...) pueda mostrar diversas cuestiones significativas sobre conflictos sociales provocados por el reparto "selectivo" del agua, que podría perjudicar en determinados momentos (en la documentación se reitera el problema del período de estío) al abastecimiento público.

\section{EL CONTROL DEL AGUA ENTRE LOS SIGLOS XIII Y XV}

A través de las fuentes documentales hemos podido diferenciar dos grandes épocas dentro de la administración del raudal desde la conquista de la ciudad hasta el siglo XV.

Desde el principio, ya fuese por el antiguo derecho de conquista, ya por el dominio eminente de los monarcas, lo cierto es que los Reyes de Castilla aparecen como los propietarios y administradores de todos los raudales que surtían de agua a la ciudad de Jaén, aunque es cierto que en la administración del de Sta. María el Concejo parece gozar de mayor autonomía a la hora de tomar las decisiones y llevar a cabo una labor administrativa, mientras que en el caso del de La Magdalena, estas debían de ser siempre corroboradas por el rey.

Esta diferencia puede deberse al valor social y político que adquirió desde el principio el raudal de La Magdalena, fundamental para la ciudad, y a que el uso intensivo del de Santa María no se producirá hasta finales del siglo $X I V$ y principios del $X V$, cuando se utilice para abastecer el arrabal de $\mathrm{S}$. Ildefonso, surgido en estos momentos, donde el Condestable Iranzo (CARRIAZO, 1940) construirá los nuevos mercados en la segunda mitad del siglo XV, dotándose ampliamente de agua a la parroquia de ese mismo nombre.

Las reformas de los Cabildos introducidas por Alfonso XI (|3|2-1350) y, especialmente, el "vacío de poder" real que se advierte en las ciudades periféricas de la corona castellana durante el reinado de Enrique IV, crearon la base para que el control del raudal pasase momentáneamente a manos de la oligarquía urbana, que parece haber olvidado que el agua de la ciudad forma parte del patrimonio real, apareciendo en la documentación municipal bajo la administración directa de los regidores que 
delegaron primero en uno de ellos y luego en dos, sistema que, pese al intento por parte de los Reyes Católicos de volver a hacerse plenamente con el control, pervivió hasta las reformas administrativas del siglo XIX.

Por otra parte, podemos diferenciar dos grandes tipos de concesiones de agua. Por un lado, las concesiones laicas, para el abastecimiento de casas particulares. Según Lázaro Damas (1988) se da la paradoja de que en las escrituras de arrendamientos urbanos localizables en las collaciones de S. Juan y Santiago, estas casas particulares con dotación de agua aparecen designadas con la palabra palacio. No obstante, hay que recordar que se denominaba así a la habitación considerada principal de las casas islámicas que tenía como función específica la de ser lugar de recepción y reunión de los varones. De ahí, y posiblemente por corrimiento semántico, pasó a designar al conjunto de ésta, pero esto no implica que se trate de lo que hoy consideramos un palacio (SALVATIERRA, en prensa). Podemos suponer que se otorgaron concesiones de agua a los herederos directos de aquellos que se establecieron en la ciudad de Jaén tras su conquista, debido a que el agua era un elemento esencial y el poderla disfrutar de forma particular, para dedicarla a montar industrias o abastecer las tierras entregadas como pago a los servicios realizados en la guerra, sería un elemento más de prestigio.

Pero quizá en estos momentos, el abastecimiento privado de particulares laicos fue menos importante que el de los establecimientos eclesiásticos, o por lo menos, las donaciones efectuadas a estos últimos son las que se han conservado en la documentación y en el tiempo. Así podemos comprobar cómo la mayoría de los conventos reciben concesiones de agua "para tiempo inmemorial". Estas instituciones eclesiásticas fueron muy abundantes en Jaén, y proliferaron desde el primer momento. Entre los más antiguos debemos citar el convento de la Trinidad, que según el Deán Martínez de Mazas (1987) fue el primer convento que se fundó en Jaén (1246), o el de la Merced (I288). Sin embargo carecemos de la documentación que señale la donación de agua a éstos.

Sí que la hemos encontrado con respecto al Real Convento de Sto. Domingo, construido al parecer sobre parte del solar de un antiguo palacio musulmán, donado a la Orden por Juan I en 1382, y al que según el Deán Martínez de Mazas (1987) dotó de varios cañones de agua; o el de las monjas de Sta. Clara, fundado en fecha imprecisa (aunque el Deán Martínez de Mazas lo data a mediados del XIII), pero del que tenemos la noticia de que por Real Cédula, Enrique III le concede en fecha dos de Abril de |39| dos doblas y media de agua del raudal de la Magdalena 2. En la misma línea estaría la efectuada por Pedro I a los claustrales de S. Francisco, de su casa y su huerto para la fundación de su convento ${ }^{3}$. Cada concesión disfrutaba del agua que se le había otorgado con verdadera prodigalidad.

Como ya indicamos, bajo el reinado de Alfonso $\mathrm{XI}$ se introdujo en toda Castilla, como parte de su política reformista, un nuevo sistema de Concejo: el Regimiento. Este cambio estaba justificado por la necesidad de evitar las luchas y desórdenes que con frecuencia se producían en los concejos abiertos. Por eso los prohibió y estableció el sistema de Concejo Cerrado. Sus componentes eran designados por el rey, recibiendo el nombre de caballeros veinticuatro, número este correspondiente a los regidores que compusieron desde muy pronto el Concejo cerrado de Jaén.

Este sistema se verá reforzado a partir de las Ordenanzas de Alcalá de Henares (1348) en las que aparece por primera vez la figura del corregidor "alcaldes de salario, regidores, vee-

2 A.H.M.J. Legajo 493. Índice de partícipes de aguas del Raudal de la Magdalena que han presentado los títulos de propiedad a la Comisión de arreglo de aguas del dicho ramal. No 94: "El convento de monjas de Santa Clara ha presentado una Real Cedula fecha dos de abril de mil trescientos noventa y uno concediendole la gracia de dos doblas y media de agua de la fuente que esta frente de la Iglesia de la Magdalena de esta ciudad".

3 A.H.M.J. Legajo $n^{\circ}$ I, I 354, Enero, 12, Sevilla. 
dores, enmendadores o corregidores" que respondían directamente ante el propio rey ${ }^{4}$.

Si bien teóricamente el nombramiento venía de la Corona, en la práctica parece que, en la mayoría de los casos, los reyes se limitaban a confirmar a los candidatos presentados y elegidos por la propia oligarquía urbana de entre ellos mismos. Se suponía que el cargo tenía carácter vitalicio, pero con el tiempo se volvió hereditario.

A partir del reinado de Enrique IV (I4541474) parece constatarse una "relajación" de la autoridad real frente a la oligarquía urbana. Los problemas políticos y sucesorios, además de los continuos enfrentamientos en la frontera impedían al monarca llevar a cabo un continuo control sobre los asuntos internos de las diferentes ciudades castellanas, entre las que se encontraba Jaén.

De esta manera es lógico plantear que ese "vacío de poder" debía ser subsanado mediante una nueva figura. En Jaén esta figura será la del Condestable D. Miguel Lucas de Iranzo (quien vivió en la ciudad desde I 460 hasta el 22 de marzo de 1473, momento en que fue asesinado), cuyo poder en la ciudad fue más allá del mundo militar insertándose de lleno en el plano político y administrativo.

A este respecto tenemos, por ejemplo, el caso de Ferrando de Gormaz quien fue nombrado regidor por elección del Condestable y que, aunque desconocemos la fecha exacta de su elección, sí que sabemos que fue sustituido por Juan de Mendoza (1476-I480)(VELASCO, 1987).

Parece que el Condestable tomó las riendas del Concejo de Jaén, dejando en un plano secundario al resto de los regidores. Apoyado por la corona, pudo hacer y deshacer a su gusto en todos los campos referentes a la ciudad de Jaén, incluidas las cuestiones de urbanismo.
Según la crónica de sus Hechos, la mayor parte de sus intervenciones urbanas se centraron en la reparación de torres y muros, pero además impulsó la estructuración de la ciudad "allanando las plaças e calles, carreras, caminos e faciendo otras muchas lauores e cosas que redundaran en grande utilidad e provecho y enobleçimiento de la dicha çibdad..." 5, prestando, según ese mismo libro, una especial atención a la expansión de la ciudad hacia la Alameda, y el ensanche de la Carrera (Arrabal de San Ildefonso), donde pudo llevar a cabo su plan urbanístico de manera íntegra al no molestarle edificios ni otras trabas interpuestas desde la antigüedad, como ocurría en el centro urbano $y$, en especial, en el barrio de la Magdalena.

Dentro de su extenso programa figuró de forma relevante el control del raudal de la Magdalena, ya que aparece como su administrador en el libro de sus Hechos, aunque no tanto para el aprovechamiento individual como para el industrial, como es el caso de los molinos:

"Y como el dicho señor Condestable vido que los
dichos molinos eran quebrados, y que la cibdad
padesçia por mengua de moliendas, usando de
su buena yndustria e grande discreçion, luego
mando proveer e dio orden como en la dicha
çibdad se fiçieron muchos molinos de mano. Y
departes de fuera de la dicha çibdad en un agua
que sale de la Madalena (...) en un agua que
sale por unos caños del muro de la dicha çib-
dad, que viene de la Madalena, de partes de
fuera, por las huertas abaxo bien cerca del dicho
muro, luego a la ora, çinco sitios o casas de moli-
nos hedifico..." 6

Este proceso no debió diferenciarse mucho del de las tenerías, muy abundantes en Jaén, de las que, según el libro de los Hechos del Condestable, él mismo adquirió varias.

Aunque no conservamos ningún documento que presente a esta figura como institución que tiene el poder de donar el agua a unos u otros propietarios, teniendo en cuenta lo expuesto

\footnotetext{
4 Peteción 47, Cortes de Alcalá de Henares, Cortes, Vol. I, pág. 608.

5 Carriazo, 1940. Tomo I, pág. 117.

6 Carriazo, 1940, Tomo Il, pág. 195 ry v.
} 
hasta aquí, en especial el hecho de que incluso llegó a nombrar a un regidor (función ésta que hasta ese momento recaía directamente en el monarca), podemos suponer que también se tomara el poder de hacer lo mismo con las aguas.

Su preocupación parece extenderse a las condiciones de salubridad de las calles de Jaén, un aspecto muy importante para nuestro estudio si tenemos en cuenta que, en estos momentos, aún había algunos arroyos y conducciones de agua que iban libremente por las calles sin encañar. Así, en vista de que las calles se encuentran con un aspecto polvoriento y pedregoso, debido a que el vecindario arrojaba la basura a la calle, y por tanto a veces también a las aguas, comenzarán a imponerse considerables penas o multas al respecto, y se comenzará una política destinada al encañamiento de los arroyos y madres que no lo estuvieran en ese momento (CARRIAZO, 1940).

No obstante este proyecto no se completará totalmente, ya que aún en el siglo XVI había algunos arroyos al descubierto, como el de S. Pedro, que circulaba por la calle actual del mismo nombre.

A la muerte del Condestable (1473), en las donaciones de agua que hemos encontrado en la documentación escrita que arranca del año 1476 en adelante, podemos observar cómo el agua se concede, en la mayoría de los casos por medio de la Ciudad, que aparece siempre con mayúsculas cuando se refiere al Concejo Municipal. Eso quiere decir que son los regidores los que deciden a quién se le concede ese bien y a quién no. Con ello, el control del agua pasa íntegramente a manos de la oligar- quía urbana que paulatinamente se ha ido haciendo con todos los resortes del poder en la ciudad, siguiendo la política emprendida por el Condestable.

Antes era uno, el rey, quien otorgaba y concedía cantidades de agua a aquellos que se hacían acreedores de sus reales mercedes. Desde la fecha citada son los regidores los que, en nombre del monarca, enajenan en todas formas cañones y plumas ${ }^{7}$ de agua y suponemos que, como era mayor el número de los que repartían y más fácil de alcanzar el favor de un regidor que el de un rey, las concesiones fueron multiplicándose, a tenor de lo que nos va a decir la documentación posterior. Todos aquellos a los que se les concede el agua eran ya de antemano personajes importantes en la sociedad, lo que podemos ver reflejado, por ejemplo, en el dato de que la mayoría, antes de acceder al cargo, ya poseían agua de la Magdalena. Así, por ejemplo, tenemos el caso de Pedro de Molina (nombrado regidor en I 480 por designación del rey para sustituir a Pedro de Leiva (|476-|480)), quien un año antes de su nombramiento ya había requerido un cañón de agua del monarca ${ }^{8}$, o el caso de Alonso Pérez de Arquellada (nombrado regidor por el monarca en sustitución de Pedro de Barrionuevo (|49|- |505)) que también había requerido del monarca una donación de agua en $14799^{9}$ que le fue concedida.

A través de las Actas Capitulares nos encontramos con que es la Ciudad la que se encarga de denunciar la ruptura de atanores, la caída de alpañales que ensucian las aguas, la mezcla con las aguas sucias que han de evitarse... Puntos claves a la hora de comprender porqué se van a encañar todos los ramales que se deri-

\footnotetext{
7 Una pluma correspondería, según el Diccionario de la Real Academia de la Lengua editado en 1984, y para la región que pertenece a la actual Barcelona, a la equivalencia de un "gasto de 25 milésimas de litro por segundo", aunque en otros sitios sea mucha más. Esta medida se presenta, por tanto, algo abstracta. Para la ciudad de Jaén hemos podido llegar a comprobar que cuatro plumas corresponden un cañón de agua. Espantaleón señala en su Memoria (1904) que "todas las arquetas que aparecen en estos primeros tramos aparecen distribuidas por medio de orificios circulares abiertos en chapa de zinc galvanizado, de ocho milímetos y medio por pluma, esto quiere decir que no disfutan de las diferentes alturas del nivel de las aguas más que en las grandes avenidas, cuándo ésta revosa por las chapas". El hecho de que estos orificios se encontraran en chapas de zinc puede relacionarse con el cambio progresivo que se realiza entre las compuertas de piedra a las de chapa. Como los partícipes siguen disfrutando de la misma cantidad de agua desde tiempo inmemorial, puede suponerse que los orificios correspondientes a la cantidad de agua de una pluma sigan siendo de las mismas dimensiones.
}

8 A.H.M.J. A.C. 1479 , Mayo, 26.

9 A.H.M.J. A.C. 1479, Julio, 4. Folio 50 v. 
ven de los grandes raudales de agua de Jaén, ante lo que no podía ser menos el de la Magdalena, que se erige como instrumento de propaganda de la clase privilegiada.

Este proceso parece ser, sin embargo, ilegal. No hemos encontrado ningún documento en el que el monarca conceda a los regidores esta facultad de actuar directamente sobre los asuntos de las aguas, así como tampoco ninguna referencia posterior que presente la Ciudad acreditando, de alguna manera, la legalidad de sus acciones, y de hecho algunos de los que reciben una donación de agua por parte de la Ciudad toman la precaución de solicitarla antes al monarca.

Este proceso de paulatino control "ilegal" en lo tocante a las aguas pudo tener como consecuencia que los Reyes Católicos pidieran en 1492 un informe al licenciado Juan de Burgos acerca de cómo había actuado el "juez de residencia" ante unas donaciones indebidas que los regidores de la ciudad habían hecho 10.

Ante este informe, los Reyes Católicos emiten ese mismo año una Real Provisión ordenando que se revisen las concesiones de agua otorgadas y "respetando las que tuvieren origen Real y aquellas en cuyo disfrute llevasen los concesionarios mas de cuarenta años, todas las demas se tuvieren por nulas y volviesen sus aguas a la Cibdad con destino a las fuentes públicas". Es, claramente, un intento de recobrar el control del raudal y de garantizar el abastecimiento público, posiblemente puesto en peligro por el incremento de las usurpaciones. También se prevé en esta pragmática "que se tapiasen unas ventanas que caían sobre el manantial, pertenecientes a las casas colindantes, para evitar que por ellas se pudiere extraer aguas ni verter inmundicias" II, lo que prueba que el problema de la contaminación seguía sin solucionarse.
Sin embargo, esta Real Provisión no fue totalmente cumplida ya que con fecha cuatro de Septiembre de 150012 dictaron otra mandando observar con todo rigor la anterior, prohibiendo a los regidores que siguieran otorgando cantidades de agua, amenazándoles con multas, y confiando el cumplimiento de las Reales Provisiones al citado Licenciado Juan de Burgos, encargado del Corregimiento de la Ciudad desde 1493 y a quien se le encarga directamente el control del agua en 1500.

Resulta interesante señalar que se trata de la misma fecha en la que los reyes otorgan la Pragmática de 9 de junio de 1500 por la que se regulaban el oficio de Corregidor.

\section{EL AGUA Y LA EXPANSIÓN DE JAÉN ENTRE LOS SIGLOS XIII-XV}

Tras la conquista, y como ya hemos visto, la ciudad de Jaén se reorganiza en collaciones, por parroquias que llegaron a tener una porción de autonomía administrativa en determinados aspectos y que siguen ocupando básicamente el mismo espacio intramuros de que disfrutaba antes. Ahora bien, comenzamos a observar un crecimiento demográfico lento pero contínuo que condujo a una macización interna de la ciudad que se complica aún más debido a las nuevas necesidades de espacio que requieren los nuevos equipamientos urbanos: fuentes, hospitales, hospicios, etc., a los que hay que agregar el mayor tamaño de las viviendas de los sectores dominantes, desde los diferentes palacios laicos, nobiliarios y burgueses a los palacios episcopales o los conventos. Para algunos sectores privilegiados, el control del agua pudo estar estrechamente relacionado con las orientaciones particulares y especulativas para orientar el crecimiento urbano hacia terrenos que poseían o hacia aquellas tierras de las que podrían recibir algunos beneficios.

\footnotetext{
IO Se encuentra recogida en el libro "Colección diplomática del Archivo Histórico Municipal de Jaén. Siglos XIV y XV" dirigido por Rodríguez Molina, J. en 1985. Documento LV. Pág. I5I-I52.

I I A.H.M.J. Legajo n I. Citadas también por Espantaleón Molina (1905, pág. 25).

12 Esta Real Provisión aparece citada en las Actas Capitulares del Archivo Histórico Municipal de Jaén, sesión de 2 de Octubre de I500, Folio 74 r.
} 
Por tanto aparece también un importante número de nuevos edificios que van a ocupar el mismo espacio intramuros. La única salida era ir colocando población extramuros, con lo que se irán creando arrabales cerca de las puertas de la ciudades. Sin embargo, para la mayoría de la población seguía siendo preferible asentarse en el interior de las murallas, no sólo por seguridad (hemos de tener en cuenta que la población seguía temiendo nuevas razzias de los nazaríes) sino que además no tenía el mismo prestigio social vivir en el interior de la ciudad que en un arrabal. Todo esto provocó que esa "apertura" de la ciudad fuese un proceso muy lento y controlado, que continuó durante el siglo XVI. El concejo debía determinar hacia dónde se crearían los arrabales (dependiendo de la topografía, de las vías de comunicación, de la línea de rigidez del agua...) y cómo lograr que la población siguiera esas mismas direcciones.

Como ya señaló Luz de Ulierte (1990), los conventos que, por no tener espacio para asentarse dentro de las murallas, se situaron junto a las puertas de la ciudad pero extramuros, jugaron un papel importantísimo en este proceso expansivo.

Pero ese proceso será complejo y contradictorio. Así, al Sur de la ciudad, en la zona conocida actualmente como barranco de los Escuderos, se situará inicialmente el llamado arrabal de las monjas, que recibió su nombre por hallarse ubicado en él el convento de Santa Clara. Pero tras la razzia nazarí de 1368 se situó intramuros, a espaldas de la Iglesia de S. Pedro, pasando a ser uno de los más ricos gracias a las concesiones que le hace Enrique II en 1371. Otros conventos ubicados inicialmente en las proximidades de las puertas de la ciudad, con una clara vocación de impulsar el crecimiento urbano hacia el exterior de la muralla serán, por ejemplo, el de los Jerónimos del que desconocemos el momento de su fundación, cuyas huertas llegaban hasta la puerta del Ángel; el de Santa María de los Ángeles, fundado en I 475 (MARTíNEZ DE MAZAS, 1749) junto a la puerta de Baeza, que adquirió una gran importancia cuando la reina católica se alojó en él, concediéndole a su marcha una serie de privilegios.

En la puerta de Martos se situaba el de la Santísima Trinidad, que según el Deán Mazas (1978) fue el primer convento que se fundó en el siglo XIII. Ya en I5I I se fundará también el de la Coronada, al exterior de la puerta de Martos.

A éstos se les irán uniendo durante el siglo $\mathrm{XVI}$ y hasta el siglo XVII, otras órdenes como la de las Carmelitas Descalzas, la fundación de los Mercedarios, el de Santa Ana o el de la Compañía de Jesús.

Pero las aguas que acapara la iglesia no sólo irán destinadas a conventos o parroquias, sino también a los hospitales. Así contamos con la noticia que nos indica que en el año "... de mil cuatrocientos noventa y siete existia el hospital [de S. Rafael] a cargo del ayuntamiento quien lo cedio al convento de Frailes de S. Juan de Dios (1619) y que este establecimiento ampliado despues con las casas de que forman el hospital todas gozaban de agua del raudal de la Magdalena sin expresar cantidad..." I3.

Sin embargo, muchas de estas iniciativas de colocar conventos extramuros para potenciar el desarrollo urbano hacia unas u otras zonas, fracasarán por diversos motivos y a finales del siglo XIV muchos de ellos se habían trasladado ya al interior de la ciudad, como el mencionado de Santa María de los Ángeles, que lo hizo cuando en 1486 el Canónigo licenciado Pedro López Nieto y su padre donaron bastantes fincas y unas casas de su propiedad localizadas junto a una pequeña iglesia llamada de S. Miguel el Nuevo, en la Calle Maestra Baja, la que hoy es Martínez Molina. Pero incluso mientras se hacían las obras de su nueva residencia, las monjas se trasladaron a unas casas situadas en el solar donde luego se edificaría el Palacio Episcopal. Ya en el nuevo convento, cuyo muro daba a la calle Maestra Baja, al callejón que luego se llamó

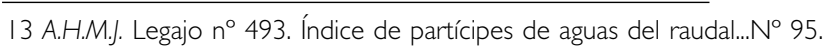


de los Ángeles y a la calle Maestra Alta, frente a la puerta lateral de la Parroquia de Santiago, se le concedió agua de la Magdalena mediante Real Provisión dada en Valladolid el trece de Agosto de 1558, y presentada ante la ciudad en 30 de Septiembre de ese mismo año ${ }^{14}$. También se trasladará al interior el de los Jerónimos en 1575 (DíEZ BEDMAR, en prensa).

En realidad sólo el arrabal de S. Ildefonso, donde se funda el convento de S. Francisco en I 354 por donación de Pedro I, como ya dijimos, llegará a consolidarse, quizá porque desde muy pronto se rodeó de una cerca, y porque hacia el mismo se dirigen los remanentes de agua de diversas fuentes de la ciudad, lo que garantizará el abastecimiento de la zona.

El marco histórico en que se inscribe esta ampliación se caracteriza por la conflictividad política y la consiguiente crisis económica. En I 406 sube al trono de Castilla D. Juan II, de dos años de edad y la doble tutela de la viuda de su padre, $D^{a}$ Catalina de Láncester y su tío, el infante D. Fernando, no tranquilizó en nada la agitada frontera.

Tras la subida al trono -de manera definitiva con su mayoría de edad- de Juan II, se dan una serie de fuertes luchas intestinas de las que se aprovechan los nazaríes atacando la frontera con Castilla. Fueron unos años sucesivos de hambres y azotes de pestes. Si los vecinos sembraban, no lo podían llegar a recoger porque los campos era quemados o arrasados; si se sufría un asedio las enfermedades proliferaban... y así sucesivamente.

En este contexto, y siendo obispo de Jaén D. Gonzalo de Zúniga, tuvo la ciudad uno de los momentos más difíciles, y fue entonces cuando tuvo lugar, según la tradición, el Descenso de la Virgen a Jaén.

En la llamada "Información de Villalpando", se narra la tradición del itinerario de la Virgen.
Según los testigos del milagro, se había detenido la procesión, se vio un altar y se sentó en un trono resplandeciente la Santísima Virgen a las espaldas de la Iglesia y Capilla mayor de la Iglesia de S. Ildefonso. Gonzalo de Zúñiga, el obispo, mandó edificar "una pequeña capilla con unas rejas de madera, junto a ella un altar, y en él una imágen de Nuestra Señora".

Jaén desde ese momento se convierte en una ciudad mariana. Fue nombrada Patrona de la ciudad esta Virgen denominada por el suceso de la capilla como Nuestra Señora de la Capilla por plebiscito unánime y secular. El pergamino original de la Información testifical del Descenso fue hecha en 13 de Junio de 1430 ante el provisor Villalpando. En el mismo año parece que se constituye una piadosa congregación o cofradía dedicada a rendirle culto y formar como una guardia de Honor para la Virgen.

Este suceso milagroso jugó, sin duda, un importante papel en la consolidación del arrabal al permitir la temprana "sacralización" del barrio. De esta manera, aunque el primer dato referencial que se ha encontrado sobre el "ordenamiento de la Capilla de San IIdefonso" está fechado en 1248 y se encuentra recogido en el "Códice Gótico" de la Catedral de Jaén ${ }^{15}$, el auge urbanístico de esta zona llegará en el siglo XV, cuando tiene lugar un conocido "descenso" de la Virgen, lo que inevitablemente dio lugar a reformas arquitectónicas en dicha parroquia, y al reforzamiento del poblamiento de la zona, ampliándose la demarcación de su feligresía varios kilómetros en dirección Norte-Nordeste ${ }^{16}$.

De esta forma la oligarquía encontró un factor extraordinario para potenciar el desarrollo urbano de esa zona.

En cualquier caso, la consolidación del mismo vendrá de la mano de la política de nuevas obras llevada a cabo por el Condestable Miguel

I 4 A.H.M.J. A.C. I558, Septiembre, 30. Folios 207 r, y 208 r.

15 Publicado por Segura Moreno, M. con el título de "Estudio del Códice Gótico (siglo XIII) de la Catedral de Jaén". Jaén, 1976.

16 Catálogo Monumental de la Ciudad de Jaén, 1985. 
Lucas de Iranzo. Éste no sólo orientó en esa dirección el raudal de Santa María, como ya señalamos, sino que también situó en esa zona varias piezas del equipamiento público de la ciudad, como el Mercado Bajo y las nuevas carnicerías, creando de esta manera una zona proclive para albergar a un número considerable de población. Por tanto se constata una decidida intervención urbanística hacia esta zona a partir del siglo XV.

Aunque carecemos de una documentación exhaustiva como la que se conserva para el siglo XVI (Figura 3), sí que podemos comprender el crecimiento urbano que se experimenta a lo largo de la Edad Media así como el aumento de la demanda de agua perteneciente a la Fuente de la Magdalena si comparamos la figura 2 y la 3.

\section{BIBLIOGRAFÍA}

ACIÉN Almansa, M. (1987) "Madinat al-Zahara en el urbanismo musulman" en Cuadernos de Madinat al-Zahara, I. Pág. | |-26.

AGUIRRE Sábada, J. ( 1982) "El Jaén islámico" W. AA. en Historia de Jaén. Jaén.

AGUIRRE, J; JIMÉNEZ, Ma C. (1979) Introducción al Jaén islámico (estudio geográfico-histórico). Jaén.

AGUIRRE Sádaba, F; SALVATIERRA Cuenca, V. (1989) "Cuando Jaén era Yayyan" en Jaén. Vol. II, Historia. Granada. Pag. 484 y ss.

BARCELÓ, M.; CARBONERO, M.A; MARTÍ, R.; ROSELLÓ-BORDOY, G. (1986) Les agües cercades. (Els qanât(s) de l'illa de Mallorca). Institut d'Estudis Baleàrics. Palma de Mallorca.

BARCELÓ, M. KIRCHNER, H. et alii. (1988) Arqueología medieval, en las afueras del "medievalismo". Barcelona.

BELZA, J. (197I) Fuentes de Granada. Obra cultural de la Caja de Ahorros de Granada.

BUTZER, K.W; MATEU, J.F; BUTZER, E.K; KRAUS, P. ( 1985$)$ "Irrigation Agrosystem in Eastern Spain: Roman or Islamic originins?" en Annals of the Association of American Geographers n ${ }^{\circ} 75$.

CARRIAZO, Juan de Mata (1940) Hechos del Condestable D. Miguel Lucas de Iranzo (Crónica del siglo XV). Edición y estudio. Espasa Calpe S.A. Madrid.

CASTILLO Armenteros, J.C; CASTILLO Armenteros, J.L. (1989), "Excavación arqueológica en la iglesia de S. Juan
(Jaén)" Anuario arqueológico de Andalucía. III Actividades de urgencia, Pág. 292-303. Sevilla 1989.

CRESSIER, P. Hidráulica rural tradicional de orígen medieval en Andalucía y Marruecos. Elementos de análisis práctico.

DíEZ Bedmar, Ma.C. (1997): El Raudal de la Magdalena y el crecimiento urbano de Jaén. Memoria de licenciatura. Inédita. Jaén.

DíEZ Bedmar, Ma.C. (en prensa): "Asentamiento y primeros pasos de la comunidad de Agustinos en la Ciudad de Jaén"

ELISSEEF, N. (1980) "El tratado físico" en La ciudad islámica. Comunicaciones cientíícas seleccionadas del coloquio de Middle Elrest Centre, Faculty of Oriental Studies. Cambridge. Ed. Serjeant. Unesco.

ESLAVA Galán, J "Importantes hallazgos arqueológicos en el manantial de la Magdalena". Diario Ideal (Jaén) 30-VIII1969 y 5-IX-1969. También en Diario Jaén 29-VIII- 1969 y $4-I X-1969$.

ESPALZA, M. (1988) "El agua en el derecho musulmán" en M. de Espalza (ed) Agua y poblamiento musulmán. Simposio de Benissa, 1987. Benissa Ayuntamiento. Pág. 9-13.

ESPANTALEÓN Molina, A. (1905) Memoria de Licenciatura leída ante la comunidad de partícipes del Raudal de la Magdalena. Jaén.

GARCÍA GRANADOS, J.A. (inédito): Documentos para una carta de riesgo arqueológico de Granada (Zona Centro-Catedral). Memoria de Licenciatura, 1998.

GLOBOT, H. (1979) Les qanâts. Une technique d'acquisition de l'eau. París.

GLICK, T.F. (1970) Irrigation and Society in Medieval Valencia. Harward University Press.

GLICK, T.F (1979) Islamic and Christian Spain in the Early Middle Ages. Comparative Pespectives on Social and Cultural Forms. Princeton University Press.

GONZÁlEZZ Alcantud, J. A; MALPICA Cuello, A. (Coords) (1995) El agua. Mitos, ritos y realidades. Coloquio Internacional. Granada 23-26 de Noviembre de 1992. Diputación Provincial de Granada.

GONZÁLEZ Jiménez, M. (1983) "Orígenes de la Andalucía cristiana". En Historia de Andalucía Vol. II. Ed. Cupsa y Planeta. Barcelona.

GONZÁLEZ, J. (1946) "La conquista de Fernando III en Andalucía". Cuaderno Hispania n 6. Madrid.

JAUBERT de Passá. F. (199|) Canales de Riego de Cataluña y reino de Valencia. Tomo I (Clásicos agrarios) Universidad de Valencia. Madrid.

KIRCHNER, H.; NAVARRO, C. (1994) "Objetivos, métodos y práctica de la Arqueología hidráulica". Arqueología y territorio medieval n०I. Págs. I59-I82. 
LADERO Quesada, M.A. (1973) Andalucía en el siglo XV. Ed. C.S.I.C. Madrid.

LASTANOSA, P.J. (1983) Los veintiún libros de los ingenios y de las máquinas. Mss. de la Biblioteca Nacional. Edición de A. García de Diego.

LÁZARO Damas, Ma S. (1988) Desarrollo histórico del casco urbano de Jaén hasta 1600. Jaén.

LÁZARO Damas, Ma S. (1987) Las fuentes de Jaén. Jaén.

LÓPEZ Cuervo, S. (198I) Medina Az-Zahira. Ingeniería y Formas. M.O.P.U. Madrid.

MADOZ, P. ( I 849) Diccionario Geográfico-Estadístico-Histórico de España. Madrid. (Vol. Facsímil preparado sobre Jaén, Valladolid, 1988).

MALDONADO, P. (1990) Arquitectura hidráulica.

MALPICA Cuello, A. Arqueología urbana de la Granada Medieval: el Darro y las tenerías del Puente del Carbón (En prensa).

MARTÍNEZ de Mazas, J. (1987) Retrato al natural de la ciudad y término de Jaén. Jaén, 1794. Reimp. del Albir, S.A., Barcelona (Ed. Facsímil).

MARTÍN Robles, Ma . V. (1986) Fuentes, pilares y algibes de Granada. Memoria de Licenciatura inédita. Granada.

MINCHÓN, J.L. (1980) "Instituciones religiosas" en La ciudad islámica. Comunicaciones científicas seleccionadas del coloquio de Middle Elrest Centre, Faculty of Oriental Studies. Cambridge. Ed. Serjeant. Unesco.

ORIHUELA Uzal, A.; VILCHES Vilches, C. (199I) Algibes públicos en la Granada islámica. Ayuntamiento de Granada.

PARDO Crespo, J.M (1978) Evolución e Historia de la ciudad de Jaén. Jaén.

PÉREZ Carpio, C. (1983) "La frontera concejo de JaénReino de Granada en 1476". Cuadernos de Estudios Medievales (Granada), Vol. X-XI. Pág. 23I-236.

PÉREZ Martínez, Ma C; Alcázar Fernández, E. (1993) "Aproximaciones al urbanismo de Jaén en el siglo Xl" en El Baño árabe del Naranjo y la formación del edificio "Los Caños" Pág. |4|-|45.

PONZ, A. (|79|) Viaje por España Tomo XVI, Madrid. Pág. 20I-202 (Ed. Facsímil. Madrid 1989, vol. IV).

QUESADA Gómez, Ma D. (1985) Uso, distribución y reglamentación de las aguas en Granada (S. XIII-XVI). Granada.

RODRÍGUEZ Molina, J. (1982) La ciudad de Jaén. Inventarios e sus documentos (1549-1727). Instituto de Estudios Giennenses (C.S.I.C.)

RODRÍGUEZ Molina,J. (1978) El reino de Jaén en la Baja Edad Media. Universidad de Granada.
RODRÍGUEZ Molina, J. ( 1982 ) "Jaén en el siglo XVI. Época de esplendor." Capítulo de la Historia de Jaén. Colegio Universitario y Excma. Diputación Provincial. Jaén.

RODRÍGUEZ Molina, J. (1974-1975) "Las Órdenes de Santiago y Calatrava en el Alto Guadalquivir". Cuadernos de estudios Medievales I y II. Granada. Pág. 59-85.

SALVATIERRA Cuenca, V; ALCÁZAR Hernández, E. (1996) "La distribución del agua en Jaén durante el período islámico". Arqueología Medieval n 4. Pág. 95-106. Mertola.

SALVATIERRA Cuenca, V; CASTILLO Armenteros, J.C; CASTILLO Armenteros, J.L. (1992) "Arqueología Urbana e Historia. El caso del Jaén Islámico". Coloquio Hispano-ltaliano de Arqueología Medieval. Pág. 109-122. Granada.

SALVATIERRA Cuenca, V. et alli. (1993) El baño árabe del Naranjo y la formación del edificio "Los Caños".

SÁNCHEZ Albornoz, C. (1974) La España musulmana según los autores islamistas y cristianos musulmanes $4^{\circ}$ edición. Madrid.

SÁNCHEZ Herrero, J. (1984) "Monjes y frailes. Religiosos y religiosas en Andalucía durante la Baja Edad Media". Actas del III coloquio de Historia Medieval Andaluz.

ULIERTE, Luz (1990) "Jaén, la ciudad y su historia". Perspectiva histórica n5. Granada

VALLVÉ Bermejo, J. (1969) "La división territorial en la España musulmana. La cora de Jaén". Al-Andalus n 34, Granada. Pág. 55- 82.

VELASCO García, C. (1987) Extracción social, relaciones y competencias de los regidores jiennenses en el siglo XV. Jaén.

VITRUBIO (1978) Los Diez Libros de Arquitectura. Edición facsímil. Barcelona.

V. AA. (1985) Catálogo Monumental de la ciudad de Jaén y su término. Jaén.

V.AA. (1995) "El agua en la agricultura de Al-Andalus" El legado Andalusí. Almería.

W.AA. (1989) "El agua en zonas áridas: Arqueología e Historia". I Coloquio de historia y medio físico. Tomo I. Almería 14-16 Diciembre de 1989. Instituto de Estudios Almerienses de la Diputación de Almería. Colección Actas $n^{\circ} 4$.

XIMÉNEZ Paton (1628) Historia de la antigua y continuada nobleza de la ciudad de Jaén. Jaén.

YVES Barel. (1975) La ciudad medieval. Sistema social-sistema urbano. Presses Universitaires de Grenoble. 


\section{RESUMEN}

Los métodos utilizados para intentar reconstruir la imágen de una ciudad determinada en el período medieval han sido muy variados, dependiendo, por ejemplo, de la existencia o no de una documentación escrita significativa, o de su conocimiento a través de dibujos o de excavaciones arqueológicas que lo hayan posibilitado. Sin embargo, hasta el momento, no se le había concedido un valor especial a la existencia de conducciones de agua (en algunos casos monumentales) como eje vertebrador de un urbanismo dependiente de éstas, capaz de determinar la ubicación de determinados edificios públicos y privados, la creación de plazas allí donde se estableciera una fuente, su papel a la hora de determinar hacia dónde debía crecer la ciudad... Pero no sólo eso, también nos procura una imágen clara de los diferentes estatus sociales, de las luchas entre nobleza y clero, y del papel del Concejo. La ciudad de Jaén, definida a través de los tiempos por su abundancia en agua, gracias al Raudal de la Magdalena, nos ha servido para comprobar la importancia de este elemento dentro de los estudios urbanísticos.

PALABRAS CLAVE: Urbanismo, Jaén, agua.

\section{ABSTRACT}

The methods used for reconstructing the picture of a determinated city through the Middle Age, have been diversed, depending on the existence or not of important written documents or the knowledge through drawings or archaeological excavations. However, until this moment, it has not been conceded a special importance to the existence of water conductions (sometimes monumental) like a support of an urban development dependent on these ones. These conductions can determinate the localization of public and private buildings, the creation of squares where public fountains were settle down, their role to determinate the growth of the city, etc. In addition, the water conductions provide us a clear view of the different social status, the fights between nobility and clergy, as well as the "Concejo" role. The city of Jaén, definited through the time by its water abundance- because of the Magdalena's one ("Raudal de la Magdalena")- has been used to check the importance of this element within the studies of a city.

KEY WORDS: Town planning, Jaén, water. 


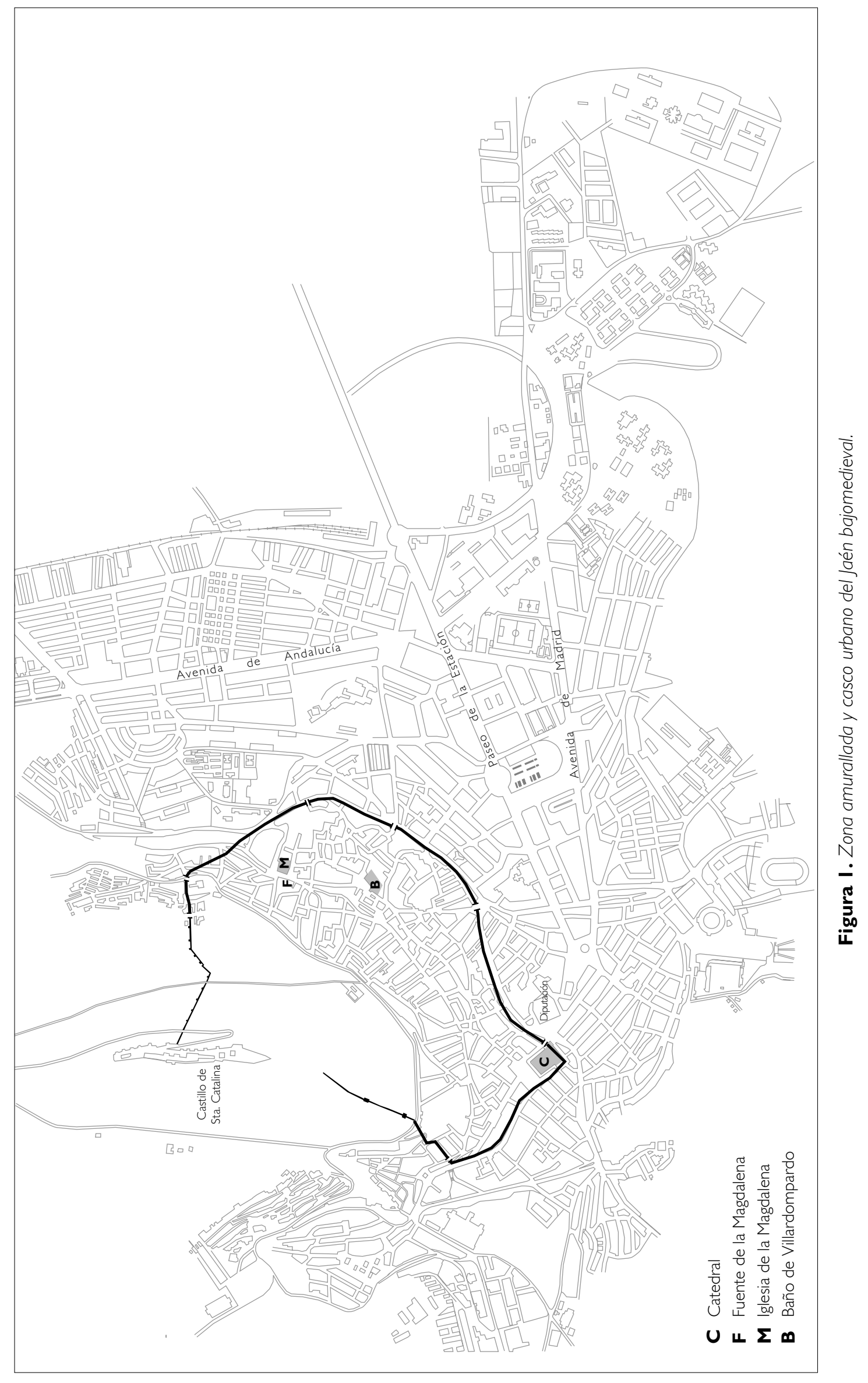




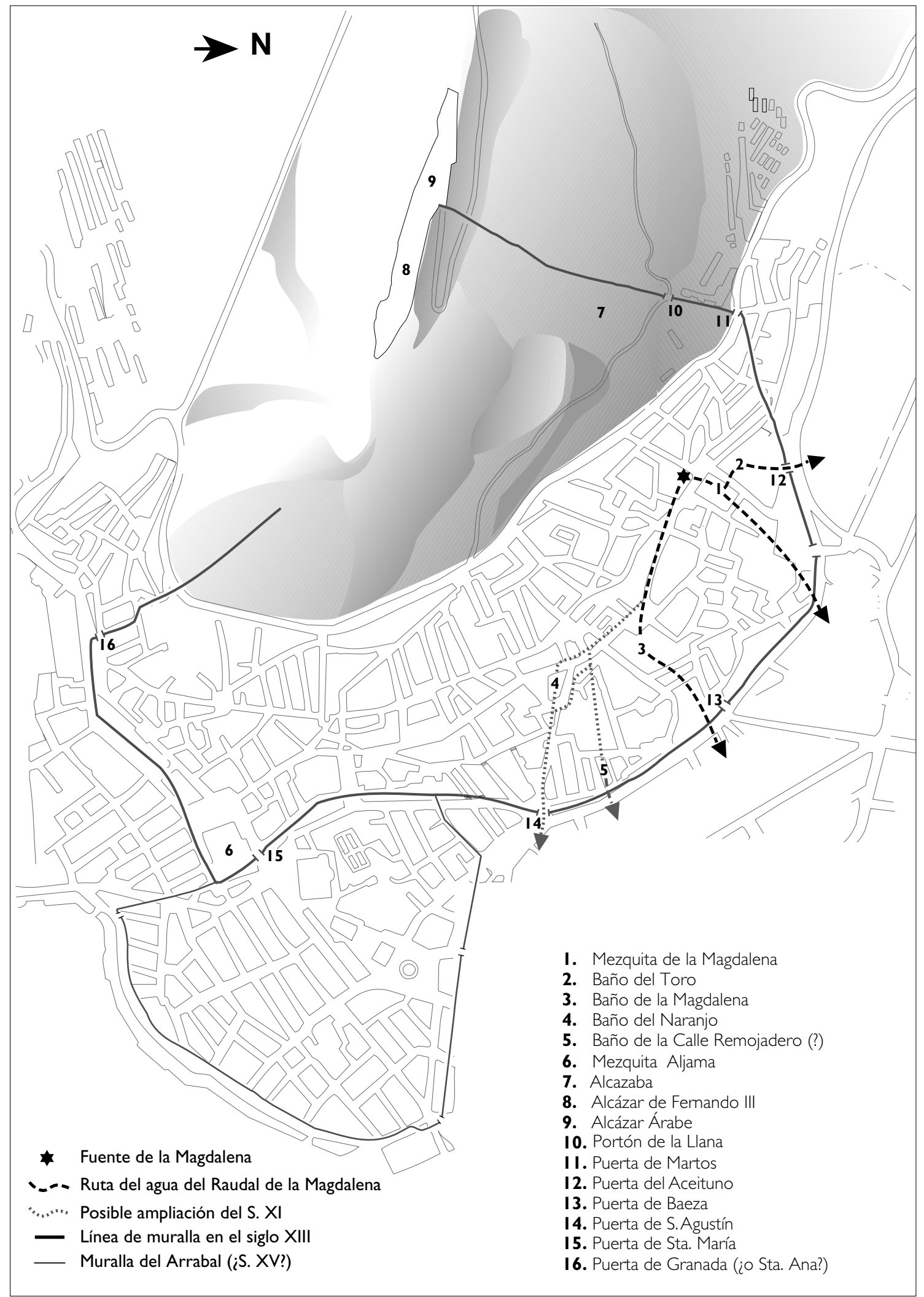

Figura 2. Conducción del agua de la Magdalena en la ciudad durante época islámica 


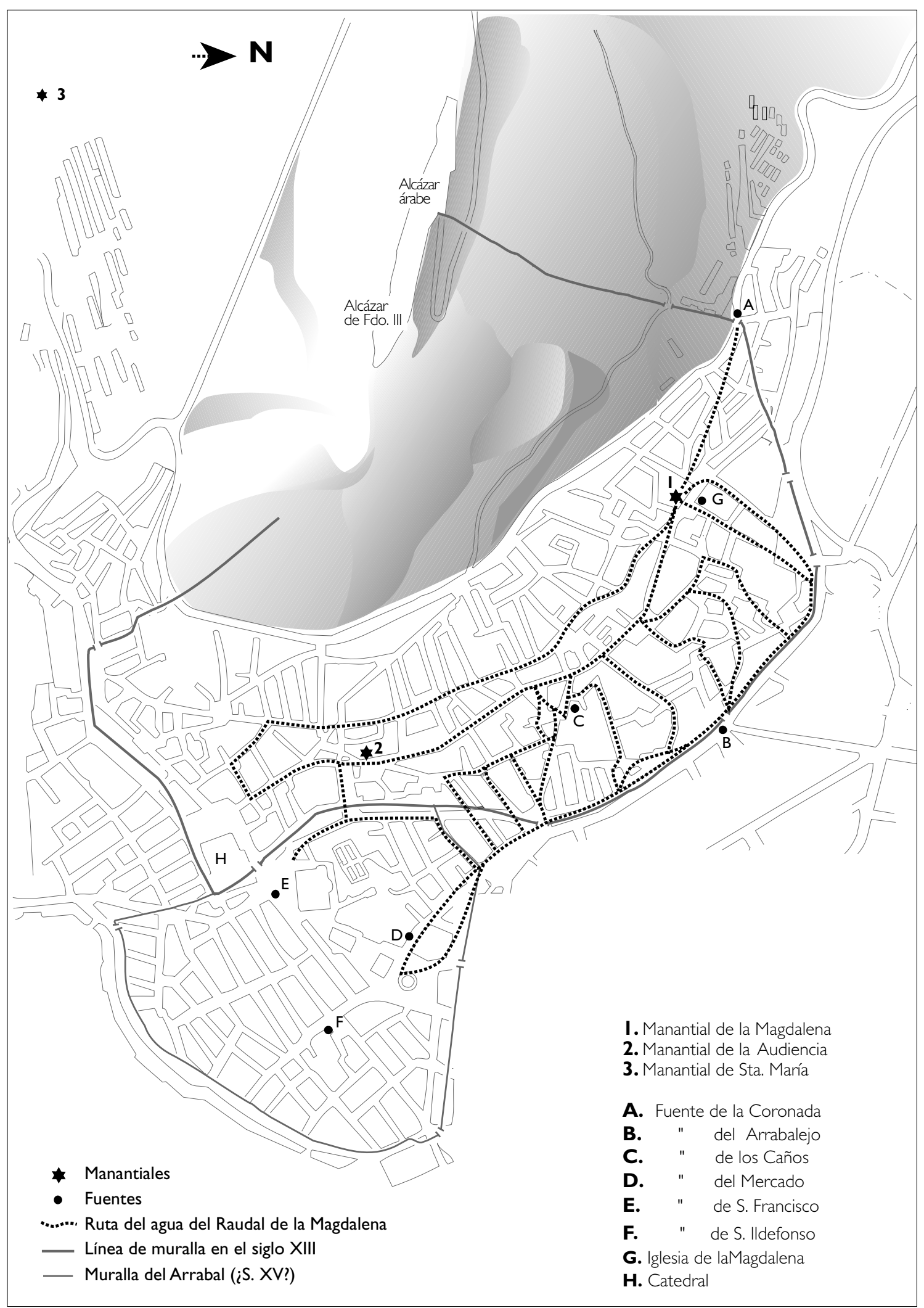

Figura 3. Conducción del agua de la Magdalena en la ciudad entre los siglos XV y XVI 


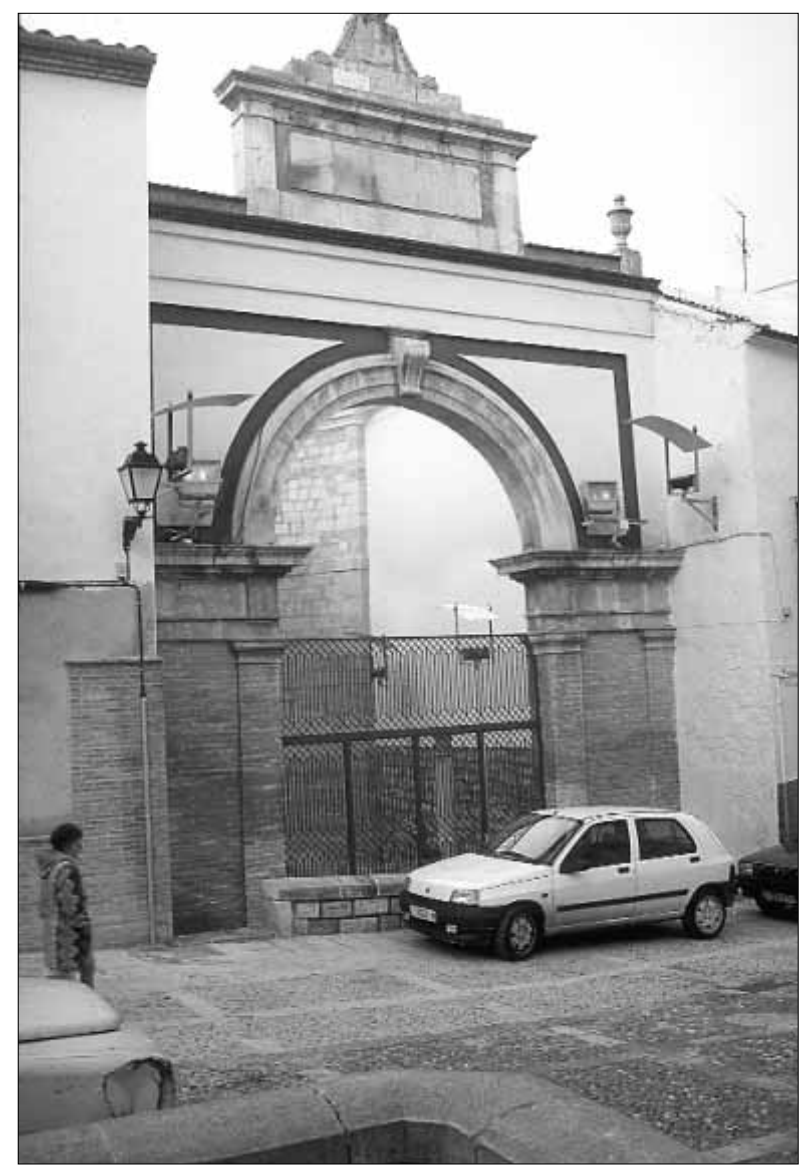

Lámina I. La Fuente de la Magdalena

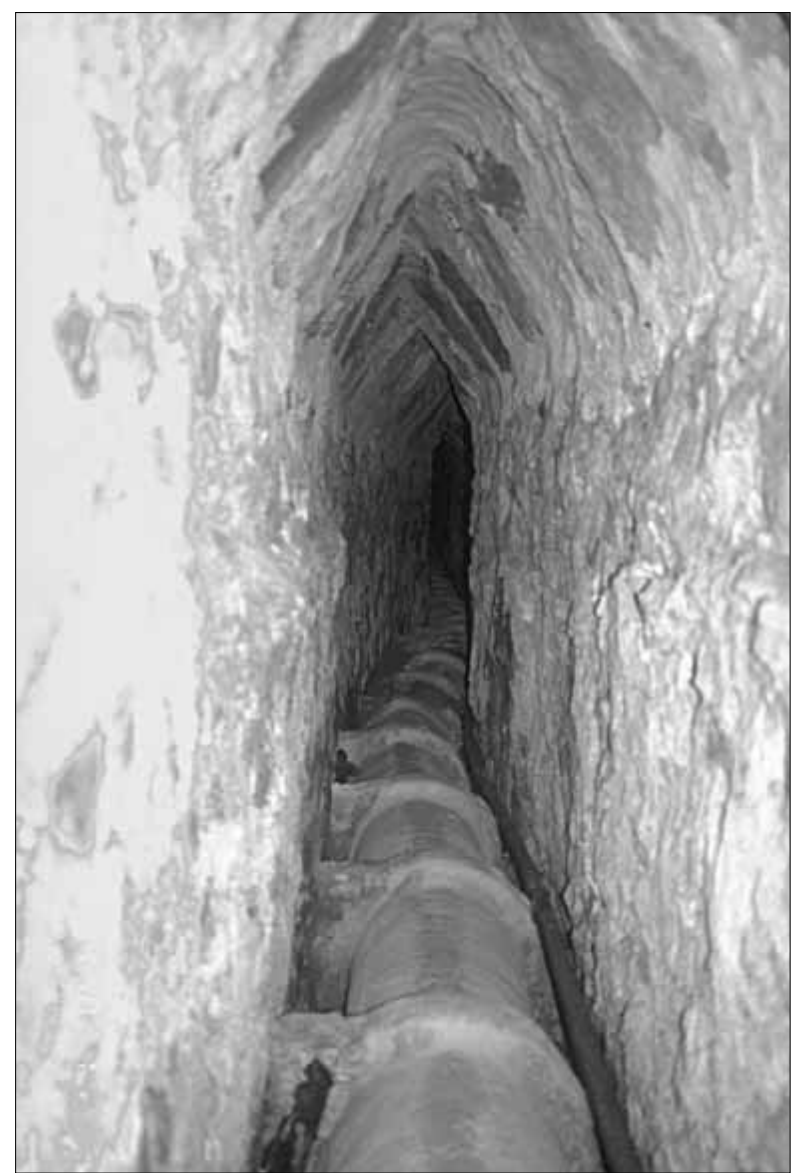

Lámina 2. Raudal de la Magdalena Excavación en el Palacio de los Uribe 